\title{
EFFECT OF SILANIZED AND NON-SILANIZED GLASS FIBER ON WATER SORPTION, SOLUBILITY AND ROUGHNESS OF HEAT CURED ACRYLIC PROSTHODONTIC AND ORTHODONTIC APPLIANCES
}

Mohamed Abdullah Quassem* and Mohamed Abdelrahman Shendy Abdelrahman**

\begin{abstract}
Introduction: water sorption, solubility and roughness are undesirable characteristics of heat cured acrylic resin.
\end{abstract}

Aim of the study: to evaluate water sorption, solubility and roughness of heat cured acrylic resin reinforced with silanized and non silanized glass fiber (5 wt $\%, 10 \mathrm{wt} \%$ \& $15 \mathrm{wt} \%$ ) Water sorption, solubility and roughness were tested according to International Standards Organization specification No. 20795-1:2013.

Materials and Methods: A total of 210 samples were used in this study. group I (Control group) conventional heat cured acrylic resin Group II: HCAR reinforced with glass fiber and Group III: HCAR reinforced with silanized glass fiber). Group II and Group III were divided into 3 subgroups according to percentage of glass fiber incorporation $(5 \%, 10 \%, 15 \%)$ by weight.

Results: The highest value of water sorption was recorded for control group; while the lowest water sorption mean value was recorded for $5 \%$ non-silanized glass fiber reinforced group. The highest roughness value was for control group, while the lowest roughness mean value was recorded for $15 \%$ silanized glass fiber reinforced group. The highest water solubility value was for control group while the lowest roughness mean value was recorded for $15 \%$ silanized glass fiber reinforced group The difference between fiber reinforced experimental and control groups was statistically significant as indicated by one-way ANOVA test $\mathrm{p}$ value $=<0.0001<0.05$ ).

Conclusion: Within the limitation of this study, reinforcing heat cured acrylic resin with silanized or non silanized glass fiber will decrease water sorption, water solubility and surface roughness mean value significantly, it is practically to be used to improve physical and mechanical properties of heat cured acrylic resin prosthodontic and orthodontic removable appliances.

KEY WORDS: Acrylic resin, Glass fiber, Silane. Sorption, Solubility and Roughness

Lecturer of Removable Prosthodontics Faculty of Dental Medicine Alazhar University

** Lecturer of Orthodontics Faculty of Dental Medicine Alazhar University 


\section{INTRODUCTION}

For many years Heat cured acrylic resin preferably used for removable prosthodontic applications this is because its adequate strength, low thermal conductivity low cost, biocompatibility, ease of processing, stability in the oral environment, acceptable aesthetics and it is free from toxicity. ${ }^{(1,2)}$

Global increase in patient seeking orthodontic treatment creates a demand for the use of acrylic resin in removable appliance such as space maintenance, habit breaking, functional appliances and orthodontic retainers. ${ }^{(3)}$

However, heat cured acrylic resin absorb water slowly over a period of time through the process of diffusion primarily because of the polar properties of the resin molecules. This may negatively affect physical and mechanical properties of the denture base, it may eventually lead to denture base expansion, weaken its strength, reduce color stability and enhance bacterial and fungal growth within the denture base. ${ }^{(4-6)}$

Glass fiber reinforcement has been found to significantly increase the flexural strength, impact strength, toughness, and hardness of acrylic resin. ${ }^{(7)}$

Silane is a chemical compound with chemical formula SiH4. Silane used as coupling agent to let glass fibers adhere to a polymer matrix and stabilizing the composite material; Silane coupling agents were also found to be effective in modifying natural fiber-polymer matrix interface and increasing the interfacial strength. ${ }^{(8,9)}$

The aim of the study was to evaluate water sorption, solubility and roughness of heat cured acrylic resin reinforced with silanized and non silanized glass fiber (5 wt $\%, 10 \mathrm{wt} \% \& 15 \mathrm{wt} \%)$.

\section{MATERIAL AND METHODS}

Controlled experimental study was carried out in the laboratory of the Prosthodontic Department Faculty of Dental Medicine Al Azhar University,
Cairo, Egypt. A total number of 210 specimens were used in this study. The specimens were divided into three groups; group I (Control group) conventional heat cured acrylic resin HCAR 30 specimens; 10 for roughness test, 10 for watersorption test and 10 for solubility test). Group II:HCAR reinforced with glass fiber and Group III:HCAR reinforced with silanized glass fiber).Group II and Group III were divided into 3 sub- groups according to percentage of glass fiber incorporation $\{(5 \mathrm{wt} \%, 10 \mathrm{wt} \% \& 15$ wt $\%$ )Each sub group consists of 10 specimens for each test ( 10 roughness test,10 water sorption test and 10 solubility test) with total 90 specimens in each of group II group III.

\section{Preparation of the specimens:}

\section{Group I ; Control group (Conventional heat cured acrylic resin):}

Following the manufacturer's instructions; a total of 30 disc specimens were fabricated from wax pattern with dimensions $(20 \pm 1 \mathrm{~mm}$ in diameter $\mathrm{x} 0.5$ $\mathrm{mm}$ in thickness) according to ISO standard number 20795-1:2013, and as described in the A.D.A. specification No 12 for denture base polymers. ]10-12[

Wax specimens were flasked; heat cured acrylic resin packed, deflasked, finished and polished.

Group II: Conventional heat cured acrylic resin with glass fibers only. It consisted of 90 specimens and divided into three sub groups:

- Sub group A: 5\% glass fibers. 10specimens for water sorption test, 10 for solubility test and 10 for surface roughness test

- Sub group B: $10 \%$ glass fibers. 10specimens for water sorption test, 10 for solubility test and 10 for surface roughness test

- Sub group C: 15\% glass fibers. 10specimens for water sorption test 10 for solubility test and 10 for surface roughness test

Following the manufacturer's instructions; a total of 90 disc specimens were fabricated from wax 
pattern with dimensions $(20 \pm 1 \mathrm{~mm}$ in diameter $\mathrm{x} 0.5$ $\mathrm{mm}$ in thickness) according to ISO standard number 20795-1:2013, and as described in the A.D.A. specification No 12 for denture base polymers. ${ }^{(10-12)}$

Glass fibers $6 \mathrm{~mm}$ length were added to acrylic powder by three percentage $5 \%, 10 \% \& 15 \%$ ratio of weight of the powder; Melter electric balance was used to weight the glass fiber in relation to the acrylic powder $^{(13)}$.

The desired weight of fibers was first mixed with a predetermined volume of methyl methacrylate liquid, and then the required weight of powder was added to the mix of liquid with glass fiber and stirred until the fibers were randomly oriented to give isotopic properties with the polymer then packed into the mold then deflasked, finished and polished ${ }^{(14)}$.

\section{Group III (Conventional heat cured acrylic resin with glass fibers and silanized coupling agent):}

A total 90 Specimens were prepared like that for group II with the same three sub groups; in addition that silanized coupling agent (Triethoxy vinyl silanized $5 \mathrm{wt} \%$ ) was added to the methyl methacrylate liquid and mixed with each other ${ }^{(14)}$.

\section{Water Sorption Test:}

Following construction each specimen was carefully removed from the mould. The resultant flashes were cut away using a sharp blade (\# 15) to avoid loose particles attached to the samples during weighing or immersion.

The specimens were transferred into a glass desiccator containing dehydrated silica gel (DesiPak,SUD CHEME, BELEN,NM) maintained at $37^{\circ} \mathrm{C} \pm 1^{\circ} \mathrm{C}$ and stored for $1 \mathrm{~h}$ then they were maintained for another hour at $23 \pm 1^{\circ} \mathrm{C}$. The specimens were then weighed using an electronic balance with four digits precision (BS150, ST Instruments. Taiwn). This cycle was repeated until constant weight was achieved i.e. dry weight or original weight.
Then, each specimen was immersed in distilled water at $37^{\circ} \mathrm{C} \pm 1^{\circ} \mathrm{C}$ in separate containers. Water sorption was assessed by weight changes. Water sorption was reported in weight percent $(\%)$. Wet weight was determined by the procedures described in the ADA specification no. 27 for resin-based materials.

Specimens were removed from water, blot-dried using filter paper and waved in air for $15 \mathrm{~s}$ to remove any apparent moisture. The final weight was taken $1 \mathrm{~min}$ from the time of removal from water. The water sorption percentage was computed as follows:

Water sorption $\%=$

$$
\frac{\text { weight gained - original weight }}{\text { original weight }}
$$

When the material is immersed in water, some of its components dissolve and are leached out of the samples. This results in a weight loss which can be measured as solubility. Therefore, to calculate the water sorption, water solubility should be measured first $^{(15)}$.

\section{Water Solubility test:}

Water solubility was measured by registering desorption of the samples that gained water after 4 weeks. Desorption was done by keeping the specimens in a firmly closed desiccator containing silica gel. The specimens were weighed weekly till six weeks where constant weights were attained. ${ }^{(9)}$

The weight after desiccation was used to calculate the water solubility percentage which represents the amount of leached material from the samples. ${ }^{(15)}$

Water solubility $=$ weight before immersion (dry weight) - weight after desiccation.

$$
\text { Water solubility } \%=\frac{\text { water solubility }}{\text { dry weight }} 100
$$




\section{Roughness methodology}

The optical profilometry tend to fulfill the need for quantitative characterization of surface topography without contact ${ }^{(16)}$.

Quantitative analysis of two-body wear on specimens and their antagonists was carried out before and after loading in a 3D-surface analyzer system. Specimens were photographed using USB Digital microscope with a built-in camera (Scope Capture Digital Microscope, Guangdong, China) connected with an IBM compatible personal computer using a fixed magnification of $120 \mathrm{X}$. The images were recorded with a resolution of $1280 \times 1024$ pixels per image. Digital microscope images were cropped to 350 x 400 pixels using Microsoft office picture manager to specify/standardize area of roughness measurement. This area was chosen on the basis of the dimension of the typical bacteria expected to adhere to composite surface in vivo ${ }^{(17)}$.

The cropped images were analyzed using WSxM software (Ver 5 develop 4.1, Nanotec, Electronica, SL) ${ }^{(18)}$ Within the WSxM software, all limits, sizes, frames and measured parameters are expressed in pixels. Therefore, system calibration was done to convert the pixels into absolute real world units. Calibration was made by comparing an object of known size (a ruler in this study) with a scale generated by the software. WSxM software was used to calculate average of heights ( $\mathrm{Ra}$ ) expressed in $\mu \mathrm{m}$, which can be assumed as a reliable indices of surface roughness. ${ }^{(19)}$ Subsequently, a 3D image of the surface profile of the specimens was created using A digital image analysis system (Image J 1.43U, National Institute of Health, USA). The unworn surface served as a reference. With this method, a 3-dimensional geometry of the worn surface was generated.

\section{RESULTS}

\section{Water sorption:}

TABLE (1) Comparison of water sorption results (Mean values $\pm \mathrm{SD}$ )

\begin{tabular}{|c|c|c|c|c|c|}
\hline \multirow{2}{*}{\multicolumn{3}{|c|}{ Variables }} & \multirow{2}{*}{$\operatorname{Mean} \pm$ SD } & \multicolumn{2}{|c|}{ ANOVA } \\
\hline & & & & $\mathbf{F}$ & Pvalue \\
\hline \multirow{4}{*}{ 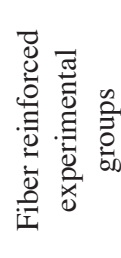 } & \multirow{2}{*}{$5 \%$} & Non & $1.3252 \pm .20585$ & \multirow{7}{*}{9.928} & \multirow{7}{*}{$<.0001 *$} \\
\hline & & Silanized & $1.9077 \pm .19888$ & & \\
\hline & \multirow{2}{*}{$10 \%$} & Non & $1.8840 \pm .56402$ & & \\
\hline & & Silanized & $1.728 \pm .17399$ & & \\
\hline & \multirow[b]{2}{*}{$15 \%$} & Non & $1.4801 \pm .75022$ & & \\
\hline & & Silanized & $1.9767 \pm 1.39442$ & & \\
\hline $\begin{array}{c}\text { Control } \\
\text { group }\end{array}$ & & & $1.9934 \pm .28421$ & & \\
\hline
\end{tabular}

Between fiber reinforced experimental and control groups* significant $(p<0.05)$

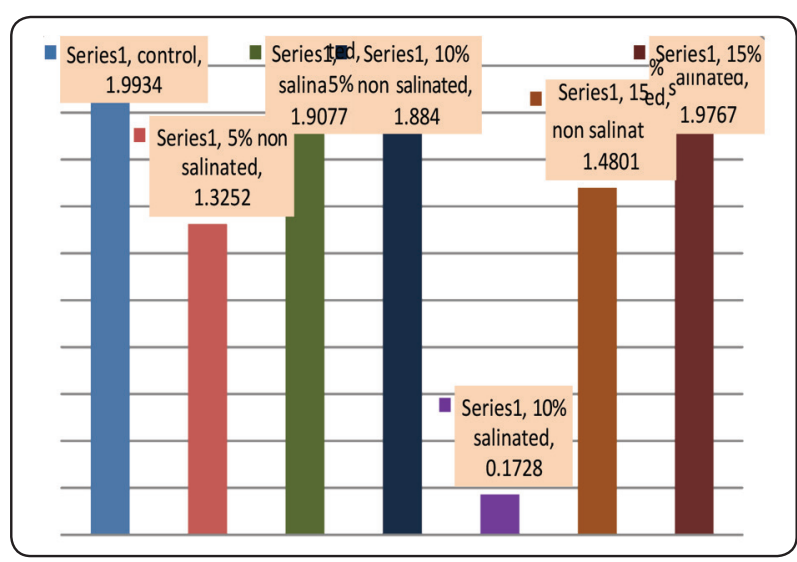

Fig. (1)

Descriptive statistics showing mean values, standard deviations (SD) for water sorption value recorded for fiber reinforced experimental and control groups are summarized in table (1) and graphically represented in figure (1).

From the data shown in table (1) it can be noted that the highest water sorption value was recorded for control group (1.9934 \pm .28$)$ followed 


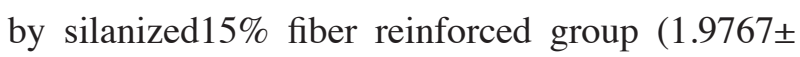
1.39442 ), followed by silanized $5 \%$ fiber reinforced group (1.9077 \pm .19$)$, followed by non-silanized

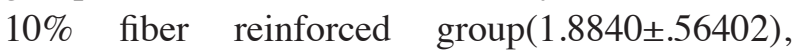
followed by silanized $10 \%$ fiber reinforced group (1.728 \pm .17$)$, followed by non-silanized $15 \%$ fiber


water sorption mean value was recorded fornonsilanized5\% fiber reinforced group (1.3252 \pm .20$)$.

The difference between fiber reinforced experimental and control groups was statistically significant as indicated by one-way ANOVA test ( $\mathrm{F}=$ $9.928, \mathrm{p}$ value $=<0.0001<0.05)$.

Pair-wise Tukey's post-hoc tests showed statistically non-significant difference $(\mathrm{p}>0.05)$ between control group and subgroups (5\% fiber reinforced non-silanized and silanized, $10 \%$ fiber reinforced non-silanized or $15 \%$ fiber reinforced non-silanized and silanized).

The difference between silanized $10 \%$ fiber reinforced subgroup and other fiber reinforced subgroups or control group was statistically significant $(\mathrm{p}<0.05)$.

\section{Water solubility:}

TABLE (2) Comparison of water solubility results (Mean values $\pm \mathrm{SD}$ )

\begin{tabular}{|c|c|c|c|c|c|}
\hline \multirow{2}{*}{\multicolumn{3}{|c|}{ Variables }} & \multirow{2}{*}{$\operatorname{Mean} \pm$ SD } & \multicolumn{2}{|c|}{ ANOVA } \\
\hline & & & & $\mathbf{F}$ & Pvalue \\
\hline \multirow{4}{*}{ 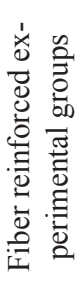 } & \multirow[b]{2}{*}{$5 \%$} & Non & $2.2919 \pm .33612$ & \multirow{7}{*}{5.207} & \multirow{7}{*}{$<.0001^{*}$} \\
\hline & & Silanated & $2.0828 \pm .21412$ & & \\
\hline & \multirow[b]{2}{*}{$10 \%$} & Non & $2.1221 \pm .32655$ & & \\
\hline & & Silanated & $2.2060 \pm .19152$ & & \\
\hline & \multirow[b]{2}{*}{$15 \%$} & Non & $1.1332 \pm .78177$ & & \\
\hline & & Silanated & $1.6450 \pm 1.28299$ & & \\
\hline \multicolumn{3}{|c|}{ Control group } & $2.3668 \pm .18812$ & & \\
\hline
\end{tabular}

Between fiber reinforced experimental and control groups* significant $(p<0.05)$

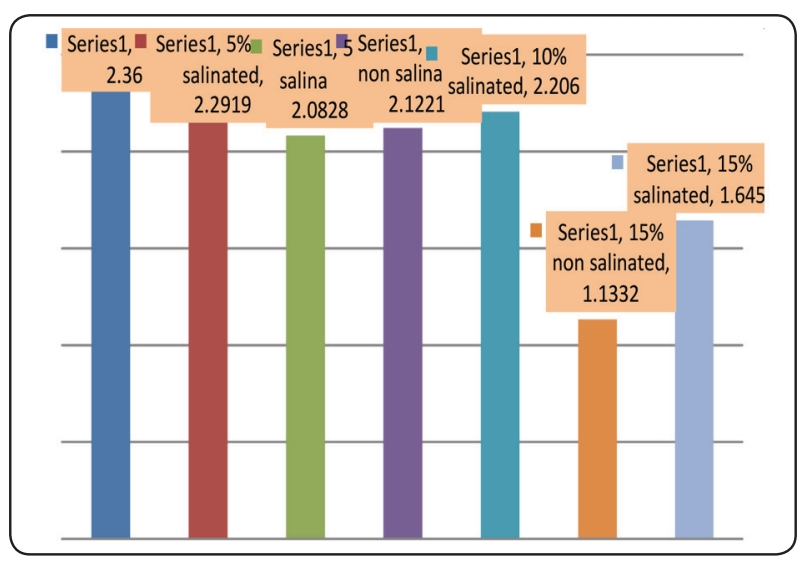

Fig. (2)

Descriptive statistics showing mean values, standard deviations (SD) for water solubility value recorded for fiber reinforced experimental and control groups are summarized in table (2) and graphically represented in figure (2).

From the data shown in table (2) it can be noted that the highest water solubility value was

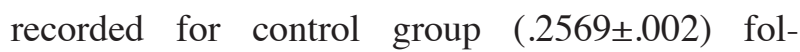
lowed by silanized $10 \%$ fiber reinforced group

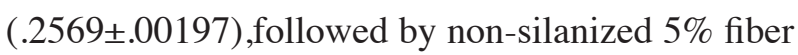
reinforced group $(.2568 \pm .00236)$, followed by silanized 5\% fiber reinforced group (.2573 \pm .00322$)$, followed by non-silanized $10 \%$ fiber reinforced group (.2565 \pm .00269$)$, followed by non-silanized

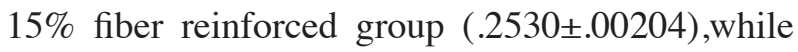
the lowest water solubility mean value was recorded forsilanized $15 \%$ fiber reinforced group $(.2529 \pm .00285)$.

The difference between fiber reinforced experimental and control groups was statistically significant as indicated by one-way ANOVA test ( $\mathrm{F}=$ 5.645 , $\mathrm{p}$ value $=<0.0001<0.05)$.

Pair-wise Tukey'spost-hoc tests showed statistically non-significant difference $(\mathrm{p}>0.05)$ between control group and subgroups (5\% fiber reinforced non-silanized and silanized, $10 \%$ fiber reinforced non-silanized and silanized or $15 \%$ fiber reinforced silanized). 
The difference between non-silanized 15\% fiber reinforced subgroup and other fiber reinforced subgroups or control group was statistically significant $(\mathrm{p}<0.05)$, except with silanized $15 \%$ fiber reinforced subgroup showed statistically non-significant difference $(p>0.05)$

The difference between silanized $15 \%$ fiber reinforced subgroup and other fiber reinforced subgroups or control group was statistically non-significant difference $(\mathrm{p}>0.05$

\section{Roughness:}

TABLE (3 ) Comparison of roughness results (Mean values $\pm \mathrm{SD}$ )

\begin{tabular}{|c|c|c|c|c|c|}
\hline \multicolumn{3}{|c|}{ Variables } & \multirow[t]{2}{*}{ Mean \pm SD } & \multicolumn{2}{|c|}{ ANOVA } \\
\hline & & & & $\mathrm{F}$ & $P$ value \\
\hline \multirow{4}{*}{ 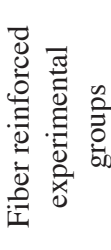 } & \multirow[b]{2}{*}{$5 \%$} & Non & $.2568 \pm .00236$ & \multirow{7}{*}{5.645} & \multirow{7}{*}{$<.0001 *$} \\
\hline & & Silanized & $.2573 \pm .00322$ & & \\
\hline & \multirow[b]{2}{*}{$10 \%$} & Non & $.2565 \pm .00269$ & & \\
\hline & & Silanized & $.2569 \pm .00197$ & & \\
\hline & \multirow[b]{2}{*}{$15 \%$} & Non & $.2530 \pm .00204$ & & \\
\hline & & Silanized & $.2529 \pm .00285$ & & \\
\hline \multicolumn{3}{|c|}{ Control group } & $.2569 \pm .00254$ & & \\
\hline
\end{tabular}

Between fiber reinforced experimental and control groups* significant $(p<0.05)$

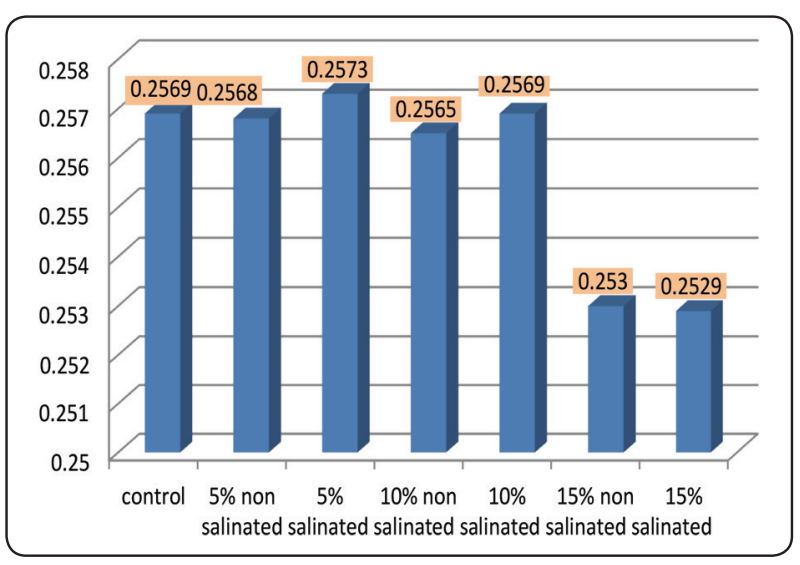

Fig. (3)
Descriptive statistics showing mean values, standard deviations (SD) for roughness value recorded for fiber reinforced experimental and control groups are summarized in table (3) and graphically represented in figure (3).

From the data shown in table (3) it can be noted that the highest roughness value was recorded for control group $(.2569 \pm .002)$ followed by silanized $10 \%$ fiber reinforced group (.2569 \pm .00197$)$,followed by non-silanized 5\% fiber reinforced group (.2568土.00236), followed by silanized5\% fiber reinforced group $(.2573 \pm .00322)$, followed by non-silanized $10 \%$ fiber reinforced group $(.2565 \pm .00269)$ , followed by non-silanized $15 \%$ fiber reinforced group (.2530 \pm .00204$)$, while the lowest roughness mean value was recorded for silanized $15 \%$ fiber reinforced group $(.2529 \pm .00285)$.

The difference between fiber reinforced experimental and control groups was statistically significant as indicated by one-way ANOVA test $(\mathrm{F}=5.645, \mathrm{p}$ value $=<0.0001<0.05)$.

Pair-wise Tukey'spost-hoc tests showed statistically non-significant difference $(\mathrm{p}>0.05)$ between control group and subgroups (non-silanized and silanized5\% fiber reinforced or non-silanized and silanized $10 \%$ fiber reinforced).

The difference between silanized and non-silanized 15\% fiber reinforced subgroups and other fiber reinforced subgroups or control group was statistically significant $(\mathrm{p}<0.05)$.

The difference between silanized 15\% fiber reinforced subgroup and non-silanized $15 \%$ fiber reinforced sub group was statistically non-significant difference $(p>0.05)$

\section{DISCUSSION}

Improvement of physical and mechanical properties of heat cured acrylic prosthesis was studied by reinforcing it with glass fibers with or without silane coupling agent. ${ }^{(9-21)}$ 
The incorporation of glass fibers to thermoset acrylic material was limited to $20 \%$ due to the deleterious effects on the mass properties above this percentage, in this study three percentages $5 \%, 10 \%$ and $15 \%$ were used. ${ }^{(22)}$

The silane coupling agent can be used to improve the adhesion of the glass fibers to the polymer. Effective impregnation allows the resin matrix to come into contact with the surface of each fiber and thus improves adhesion. ${ }^{(23)}$

It was found that addition of glass fiber with or without silane coupling agent to heat cured acrylic resin decreased water sorption, water solubility and surface roughness mean values significantly. These findings could be explained as glass fiber addition decrease the distance between polymer chains in the cross-linking chain structure of the heat cured acrylic resin so that decrease water enters into denture base material through the process of diffusion. (24)

Irrespective of silane application, the addition of $5 \%$ fiber recorded significantly lower water sorption mean values than $10 \%$ and $15 \%$ fiber addition. Addition of $5 \%, 10 \%$ and $15 \%$ glass fiber decreased water sorption mean values non-significantly. These results come in agree with Valittu P., et al, (2003); he stated that the lowest water sorption among the group added fiber 1\%,3\% and 5\% were in the group added fiber $5 \%$, the results showed that the number of glass fibers concentrations were added affect the value of water sorption. ${ }^{(25)}$

Also, Al-Vurakarra VR. (2006) states that water sorption is significantly reduced with the addition of glass fibers on the polymethyl methacrylate material. (26)

Regardless of fiber concentration, it was found that silane application decreased the water sorption strength significantly. The difference between silanized $10 \%$ fiber reinforced subgroup and other fiber reinforced subgroups or control group was statistically significant These results come in agree with Moreno MV et al. he stated that the Silanized glass fiber was found to be biocompatible when added to heat-cured resins. It reduce porosity and improve significantly the flexural strength, impact strength, toughness, and hardness of acrylic resin. (27)

Irrespective of silane application, the addition of $15 \%$ fiber recorded significantly lower solubility mean values than $10 \%$ and $5 \%$ glass fiber. The difference between non-silanized $15 \%$ fiber reinforced subgroup and other fiber reinforced subgroups or control group was statistically significant $(\mathrm{p}<0.05)$, except with silanized $15 \%$ fiber reinforced subgroup showed statistically non-significant difference $(\mathrm{p}>0.05)$.

Regardless of fiber concentration, it was found that silane application decreased water solubility non-significantly. The difference between silanized $15 \%$ fiber reinforced subgroup and other fiber reinforced subgroups or control group was statistically non-significant difference.

This results come in agreement with Miettinen VM et at, who stated that Glass fiber reinforcement reduced water sorption and solubility values of the PMMA specimens. ${ }^{(28,29)}$

Also come in agreement with Söderholm KJ who stated that, solubility behavior of acrylic resin materials will be affected by type concentration and treatment of the reinforcing filler like glass fiber and silane coupling agent. ${ }^{(30)}$

Irrespective of silane application, the addition of $15 \%$ fiber recorded significantly lower roughness mean values than $10 \%$ and $5 \%$ glass fiber. The difference between non-silanized $15 \%$ fiber reinforced subgroups and other fiber reinforced subgroups or control group was statistically significant.

Regardless of fiber concentration, it was found that silane application decreased roughness significantly. The difference between silanized and non-silanized $15 \%$ fiber reinforced subgroups and other fiber reinforced subgroups or control group was statistically significant $(\mathrm{p}<0.05)$. The difference 
between silanized 15\% fiber reinforced subgroup and non-silanized 15\% fiber reinforced subgroup was statistically non-significant difference $(\mathrm{p}>0.05)$. These results may be due to close adaptation between Silanized glass fiber and heat-cured acrylic resin.

These results come in disagreement with Raghdaa Kareem Jassim et al, who revealed that Addition of Silanized Aluminum Silicate Composite Filler to Heat Cure Acrylic Resin showed a highly significant increase in surface roughness, this may be due to differences in particle roughness and microstructure of aluminum silicate compared to heat cure acrylic matrix. ${ }^{(31)}$

\section{CONCLUSION}

Within the limitation of this study, reinforcing heat cured acrylic resin with silanized or non silanized glass fiber will decrease water sorption, water solubility and surface roughness mean value significantly, it is practically to be used to improve physical and mechanical properties of heat cured acrylic resin prosthodontic and orthodontic removable appliances.

\section{REFERENCES}

1. Raghdaa Kareem Jassim, AseelAbdulameerRadhi Evaluation of Some Properties of Heat Cure Acrylic Resin after the Addition of Salinated Aluminum Silicate Composite Filler Volume 6 Issue 7, July 2017

2. Alla R, Raghavendra KN, Vyas R, Konakanchi A. Conventional and contemporary polymers for the fabrication of denture prosthesis: part I - overview, composition and properties. Int J Appl Dent Sci. 2015;1:82-89.

3. Santos, R. L.; Pithon, M. M.; Carvalho, F. G.; Ramos, A. A. S.; Romanos, M. T. V. Mechanical and biological properties of acrylic resins manipulated and polished by different methods. Braz. Dental J. RibeirãoPreto, v. 24, n. 5, p. 492-497, Sep-Oct. 2013.

4. Pekka K. Vallittu, Varpu M. MiettinenWater sorption and solubility of glass fiber-reinforced denture polymethyl methacrylate resinInt J Nanomedicine. 2017; 12: 3801-3812.
5. Pollat TN., Valitu P. Water sorption, solubility and dimensional changes of denture base polymers reinforced with short glass fibers. Journal of biomater appl. 2003 ; 17: 321-35.

6. Powers JM., Sakaguchi RL. Craig's Restorative dental materials. Ed-12.Mosby Elsevier, St. Louis. Missouri. 2006:514 - 36 .

7. Singh K, Sharma SK, Negi P, Kumar M, Rajpurohit D, Khobre P. Comparative evaluation of flexural strength of heat polymerized denture base resins after reinforcement with glass fibers and nylon fibers: An in vitro Study. Adv Hum Biol. 2016;6:91-94.

8. Yunus N., et al. "Some flexural properties of a nylon denture base polymer". Journal of Oral Rehabilitation 32.1 (2005): $65-71$.

9. Quassem MA, Baraka Y, Helaly AO and Shoeib MA Effect of Silanated and Non-Silanated Glass Fiber on the Impact and Flexural Strength of Acrylic Denture Base".EC Dental Science 18.6 (2019).

10. Shah J, Bulbule N, Kulkarni S, Shah R, Kakade D. Comparative evaluation of sorption, solubility and microhardness of heat cure polymethylmethacrylate denture base resin \& flexible denture base resin. Journal of Clinical and Diagnostic Research. 2014;8(8):ZF01-04

11. Khan AS,Azam MT, Khan M, Mian SA, Rehman IU.An update on glass fiber dental restorative composites: A systematic review. Materials Science and Engineering . 2015;47:26- 39

12. 12-F.Mccabe J, W.G.Walls A. Applied dental materials. 2008:111-12.

13. Sanada K, Itaya N, Shindo Y. Self-healing of interfacial debonding in fiber-reinforced polymers and effect of microstructure on strength recovery. Open Mechanical Engineering.

14. Kansu G, Kalyoncuoğlu T, Uyar P, Uzun E. Cell death induced by eluates from hypoallergenic denture base acrylic resins in NIH-3T3 fibroblast cells. Journal of Dental Sciences. 2014;9(4):381-7.

15. Mohammed Abdullah Quassem and Hamada Zaki Mahross, Porosities and Solubility for Different Non-Metallic Denture Base MaterialJournal of Clinical and Diagnostic Research, 2018, Oct, Vol-12(10)

16. Ossama B. Abouelatta. 3D Surface Roughness Measurement Using a Light Sectioning Vision System. Proceedings of the World Congress on Engineering 2010 VolI ).

17. Giacomelli L, Derchi G, Frustaci A, Bruno O, Covani U, Barone A, De Santis D and Chiappelli F. Surface Roughness of Commercial Composites after Different Polishing Protocols: An Analysis with Atomic Force Microscopy The Open Dentistry Journal, 2010, 4, 191-194 
18. Horcas I, Fernandez R, Gomez JM, Colchero J, GomezHerrero J, and Baro AM, Review of Scientific Instruments. 2007;78; 013705).

19. Kakaboura A, Fragouli M, Rahiotis C, et al. Evaluation of surface characteristics of dental composites using profilometry, scanning electron, atomic force microscopy and glossmeter. J Mater Sci Mater Med 2007; 18: 155-63.

20. Karacaer Ö., et al. "The effect of length and concentration of glass fibers on the mechanical properties of an injection-and a compression-molded denture base polymer". The Journal of Prosthetic Dentistry 90.4 (2003): 385-393.

21. Lee SI., Kim CW., Kim YS.Effect of chopped glass fiber on the strength of heat-cured PMMA resin.J Korean AcadProsthodont. 2001; 39(6): 590-6.

22. Hargreaves A. "The effects of cyclic stress on dental polymethylmethacrylate". Journal of Oral Rehabilitation 10.1 (1983): 75-85.

23. Zakir M., et al. "The Role of Silane Coupling Agents and Universal Primers in Durable Adhesion to Dental Restorative Materials-a Review". Current Oral Health Reports 3.3 (2016): 244-253.

24. Kortrakulkij K. Effect of denture cleanser on color stability and flexural strength of denture base materials.Thesis.Mahidol, Thailand: Mahidol University. 2008: 4-18.
25. Pollat TN., Valitu P. Water sorption, solubility and dimensional changes of denture base polymers reinforced with short glass fibers.Journal of biomater appl. 2003 ; 17: 321-35.

26. VurakkaraVR., 2006. An in-vitro study to evaluate the effect of thickness of different heat cured acrylic denture base materials on water sorption, linear dimensional change and warpage.Dissertation. K.L.E Society's institute of dental science. Belgaum,Karnataka. : 1-56.

27. Moreno MV, Acosta-Torres LS, Barcel O-Santana FH, Vanegas-Lanc RD, Plata-Rodríguez ME, Casta VM. Fiberreinforced nano-pigmented poly (methyl methacrylate) as improved denture base. J ApplPolym Sci. 2012;126:289-296

28. Miettinen VM, Valittu PK: Water sorption and solubility of glass fiber- reinforced denture polymethyl methacrylate resin. Journal of Prosthetic Dentistry,1997; 77: 531-534

29. Miettinen VM, Narva KK, Valittu PK:, solubility and effect of post curing of glass fiber reinforced polymers. Biomaterials, 1999; 20:1187-1199.

30. Söderholm KJ: Degradation of glass filler inexperimental composites. Journal of Dental Research,1981; 60: 1867-1875.

31. Raghdaa Kareem Jassim, AseelAbdulameerRadhi , Evaluation of Some Properties of Heat Cure Acrylic Resin after the Addition of Salinated Aluminum Silicate Composite Filler International Journal of Science and Research Volume 6 Issue 7, July 2017 